\title{
Improved survival rate in patients with diabetes and end-stage renal disease in Denmark
}

\author{
V. R. Sørensen • E. R. Mathiesen • J. Heaf • \\ B. Feldt-Rasmussen
}

Received: 25 August 2006 / Accepted: 8 January 2007 / Published online: 28 February 2007

(C) Springer-Verlag 2007

\begin{abstract}
Aims/hypothesis We investigated the survival rate of Danish diabetic patients with end-stage renal disease (ESRD) between 1990 and 2005 and evaluated possible predictors of survival rate.

Materials and methods Data were obtained from the Danish National Register on Dialysis and Transplantation and from the Scandiatransplant database. Survival rates in different patient groups and association with age, sex, calendar time, waiting-list status and renal transplantation were evaluated using a multivariate Cox regression model. Results During the study period 8,421 patients (13\% type 1 diabetic, $9 \%$ type 2 diabetic and $78 \%$ non-diabetic) started renal replacement therapy. The overall survival rate improved by $15 \%$ per five calendar years (hazard ratio $[\mathrm{HR}]=0.85,95 \%$ CI: $0.81-0.88$ ). The percentage of patients within each group who received renal transplantation was: type 1 diabetic: $26 \%$, type 2 diabetic: $5 \%$, non-diabetic: $24 \%$. The survival rate of transplanted patients with diabetes mellitus (types 1 and 2) compared with nondiabetic patients at 1 year was: 95 vs $93 \%$, at 5 years: 80 vs $85 \%$ and at 10 years: 52 vs $71 \%$. Among diabetic patients survival rate was better in transplanted than in waiting-list
\end{abstract}

V. R. Sørensen $(\bowtie) \cdot$ B. Feldt-Rasmussen

Department of Nephrology, Copenhagen University Hospital,

Blegdamsvej 9,

DK-2100 Copenhagen, Denmark

e-mail: vr.soerensen@rh.dk

E. R. Mathiesen

Department of Endocrinology, Copenhagen University Hospital,

Copenhagen, Denmark

J. Heaf

Department of Nephrology, Herlev University Hospital,

Herlev, Denmark patients $(\mathrm{HR}=0.21,95 \%$ CI $0.13-0.34)$, whereas the survival rate in waiting-list patients seemed to be superior to the survival rate among non-transplantation candidates $(\mathrm{HR}=0.75,95 \%$ CI $0.53-0.1 .02, p=0.07)$.

Conclusions/interpretation The survival rate of diabetic patients with ESRD has improved during the last 15 years. Although some selection bias may exist, significantly improved survival rate was observed among transplanted patients compared with dialysis patients on the waiting-list for transplantation. Renal transplantation should therefore be offered to diabetic patients with ESRD whenever possible.

Keywords Diabetes · Dialysis · End-stage renal disease Graft survival rate · Improvement of survival rate $\cdot$ Mortality risk - Renal replacement therapy - Renal transplantation .

Survival rate $\cdot$ Transplantation waiting-list

$\begin{array}{ll}\text { Abbreviations } \\ \text { DNR } & \begin{array}{l}\text { Danish National Register on regular Dialysis and } \\ \text { Transplantation }\end{array} \\ \text { EDTA } & \begin{array}{l}\text { European Dialysis and Transplantation } \\ \text { Association }\end{array} \\ \text { ESRD } & \begin{array}{l}\text { end-stage renal disease } \\ \text { hazard ratio }\end{array} \\ \text { RR } & \text { renal replacement therapy } \\ \text { ST } & \text { Scandiatransplant }\end{array}$

\section{Introduction}

The treatment of diabetic patients with nephropathy has improved markedly during the past 20 years. Several randomised clinical studies have shown that lowering of blood pressure, blockade of the renin-angiotensin system, 
improved glycaemic control, lowering of cholesterol and correction of lifestyle can prevent or postpone the development of end-stage renal disease (ESRD) as well as cardiovascular diseases [1-8]. Thus the mean age among diabetic patients who are starting renal replacement therapy (RRT) in Denmark has increased continuously since 1990 and the incidence of diabetic patients referred for RRT has been stable since 2003 [9]. Hence, it seems that the efforts to prevent progression to ESRD among patients with diabetes are successful. However, it is not known whether the outcome after occurrence of ESRD in Denmark has also improved.

The effect of renal transplantation on life expectancy is controversial. The survival rate in patients who receive a renal transplantation is dramatically better than in patients who are treated with dialysis, even when corrected for age and renal diagnosis. However, the transplanted patients are highly selected and besides being younger, they are also healthier and of higher socioeconomic status [10, 11]. Several studies have shown that renal transplantation improves quality of life, but due to the lack of prospective randomised studies, the survival rate benefit of transplantation has not been proved. In 1999 Wolfe et al. [12] found that the unadjusted annual death rates for all dialysis patients, such patients on the transplantation waiting-list and patients who actually received a renal transplantation from a deceased donor were 16.1, 6.3 and 3.8 deaths per 100 patient-years, respectively.

Due to a high prevalence of cardiovascular diseases in diabetic patients with ESRD, the examination programme prior to entering the waiting-list for renal transplantation is more meticulous and the number of diabetic patients who receive transplantation therefore tends to be limited. Also of potential significance is the reluctance of some doctors to offer renal transplantation to diabetic patients, due to the poor survival rate described in the literature. Thus Locatelli et al. [13] found that the proportion of diabetic patients with ESRD who had received a renal transplantation was only $16 \%$ in the United States and $6.0-8.4 \%$ in Italy.

To clarify whether the survival rate of diabetic patients with ESRD has improved and to investigate the impact of renal transplantation on the survival rate, we performed an epidemiological study from 1990 to 2005 .

\section{Subjects and methods}

Study organisation The Danish National Register on regular Dialysis and Transplantation (DNR) was founded in 1990 and since then all patients actively treated for ESRD in Denmark have been registered. The register forms the basis of the Danish section of the European Dialysis and Transplantation Association (EDTA)-register and contains: date of birth, sex, renal diagnosis using standard EDTAterminology, start-day of ESRD, treatment modality (haemodialysis, peritoneal dialysis or transplantation), date of change in treatment modality, end-date (death, lost to follow-up or end of study), cause of mortality, date of graft loss and cause of graft loss. The Scandiatransplant database (ST) was founded on 1 August 1994. Since then all Danish patients placed on the waiting-list for renal transplantation or having received living or deceased donor transplantation have been registered in the ST database. The database contains: date of birth, date of entry on the waiting-list, end-date and end-cause (transplantation, death or permanently withdrawn).

Data from ST were merged with data from DNR using the social security number, which is unique and common to both databases. The analyses of all patients in the DNR database from 1990 to 2005 were conducted according to the 'intention to treat' method. Therefore patients who had ever received a renal transplantation were categorised as 'transplanted' patients, even if the kidney never functioned, while the remaining patients, who were only treated with dialysis (including both haemodialysis and peritoneal dialysis), were categorised as 'dialysis patients.' The analyses of the effect of waiting-list status were also conducted according to the 'intention to treat' method and therefore patients who at any time had ever been on the waiting-list but were never transplanted were categorised as 'waiting-list' patients, even if later they were permanently or temporarily withdrawn. Patients who received deceased or living donor transplantation were categorised as 'transplanted' patients even if the kidney never functioned. The remaining patients, who were never on the waiting-list and were only treated with dialysis (including both haemodialysis and peritoneal dialysis), were categorised as 'nontransplantation candidates'. We found similar results when patients were categorised according to the 'as treated' method (data not shown). Only first transplantations were analysed.

Due to the different start dates of the two databases, the survival rate analyses for treatment modality were only made for patients who started RRT later than 1 August 1994, whereas all other analyses were made for all patients in the RDT database as of 1 January 1990. In addition, patients were divided into three time periods according to the start-day of ESRD. Patients in time period 1 started treatment between 1 January 1990 and 31 December 1994, those in time period 2 between 1 January 1995 and 31 December 1999, and those in time period 3 between 1 January 2000 and 31 December 2004. The brain-death criterion was introduced in Denmark on 13 June 1990, and since that day, all deceased kidneys have come from heartbeating donors. The Danish Data Protection Agency and The Danish Society of Nephrology approved the study. 
Table 1 Demographic data in all 8,421 patients treated for ESRD in Denmark between 1990 and 2005, divided according to diabetes status

\begin{tabular}{|c|c|c|c|c|c|c|}
\hline & \multicolumn{2}{|c|}{$\begin{array}{l}\text { Type } 1 \text { diabetic patients } \\
(n=1,105)\end{array}$} & \multicolumn{2}{|c|}{$\begin{array}{l}\text { Type } 2 \text { diabetic patients } \\
(n=718)\end{array}$} & \multicolumn{2}{|c|}{$\begin{array}{l}\text { Non-diabetic patients } \\
(n=6,598)\end{array}$} \\
\hline & Mean (SD) & $n$ & Mean (SD) & $n$ & Mean (SD) & $n$ \\
\hline Age in time period 1 (years), $n=2,002$ & $47.1(12.9)$ & 315 & $62.9(8.5)$ & 78 & $54.8(16.7)$ & 1,609 \\
\hline Age in time period 2 (years), $n=2,814$ & $50.4(13.3)$ & 389 & $65.3(9.5)$ & 219 & $58.2(17.2)$ & 2,206 \\
\hline Age in time period 3 (years), $n=3,605$ & $52.8(14.0)$ & 401 & $67.6(9.4)$ & 421 & $61.8(16.7)$ & 2,783 \\
\hline Sex $($ male \%) & 62 & & 64 & & 62 & \\
\hline
\end{tabular}

Statistical analyses Survival rate analyses were performed using the Kaplan-Meier method and groups were compared by log-rank test. Data were analysed with a proportional hazards model (Cox model) with time since ESRD as underlying timescale. Transplanted patients did not enter the risk set until date of transplantation (delayed entry). Results are given as hazard ratios (HR) and 95\% CI, and were adjusted for age, sex, diabetes, waiting-list status, transplantation and time period. A HR $<1$ denotes a better survival rate in the first group than in the second group, a HR $>1$ denotes a poorer survival rate in the first group than in the second group. Values of $p<0.05$ were considered significant. Continuous variables were compared using Student's $t$ test and categorical variables were compared using chi-square analyses. All statistical analyses were performed using SAS, 9.1 (SAS Institute, Cary, NC, USA) and figures were generated using the statistical package Statistica (StatSoft, Tulsa, AZ, USA).

\section{Results}

All ESRD patients combined A total of 8,421 patients $(13 \%$ with type 1 diabetes, $9 \%$ with type 2 diabetes and $78 \%$ without diabetes) started treatment for ESRD during the study period. The mean age at onset of ESRD increased significantly during the three time periods, both in diabetic and in non-diabetic patients (Table 1). The overall unadjusted survival rate was significantly poorer in type 1 and type 2 diabetic patients than in non-diabetic patients (Fig. 1). A multivariate Cox regression model including age, sex, diabetes, type of diabetes, transplantation and time period as predictors of the survival rate demonstrated that the mortality risk was $67 \%$ higher in type 1 diabetic patients than in non-diabetic patients (Table 2). The survival rate in type 1 and type 2 diabetic patients was comparable and the overall survival rate improved by $18 \%$ from time period 1 to time period 2 and by $14 \%$ from time period 2 to time period 3 . There was a significant interaction between time period and ESRD treatment (dialysis or transplantation) $(p<0.001)$ and between time period and presence of diabetes $(p<0.001)$. For this reason
Table 3 shows the effect of time period in both dialysis and transplanted patients and in diabetic and non-diabetic patients in time period 2 vs time period 1 and in time period 3 vs time period 2. The survival rate in diabetic patients treated with dialysis improved by 19 and $17 \%$ for each time period, respectively, whereas the survival rate among diabetic transplanted patients improved by 53 and $58 \%$. The improvement among transplanted diabetic patients in time period 3 vs the second time period was not statistically significant. The share of incident type 2 diabetic patients with ESRD increased during the study period from $4 \%$ in time period $1-8 \%$ in time period 2 and $12 \%$ in time period 3 . A total of 681 type 2 diabetic patients were treated with only dialysis and 37 patients received renal transplantation. In a multivariate Cox regression analysis correcting for age, sex and transplantation, the overall survival rate in type 2 diabetic patients improved by $31 \%$ from time period 1 to time period $2(\mathrm{HR}=0.69,95 \%$ CI $0.52-0.91, p<0.01)$ and by $18 \%$ in time period 2 to time period $3(\mathrm{HR}=0.82,95 \% \mathrm{CI} 0.67-1.01, p=0.06)$.

A total of 4,740 patients died during the period of observation. Cardiac and vascular diseases accounted for approximately $50 \%$ of the deaths and were significantly

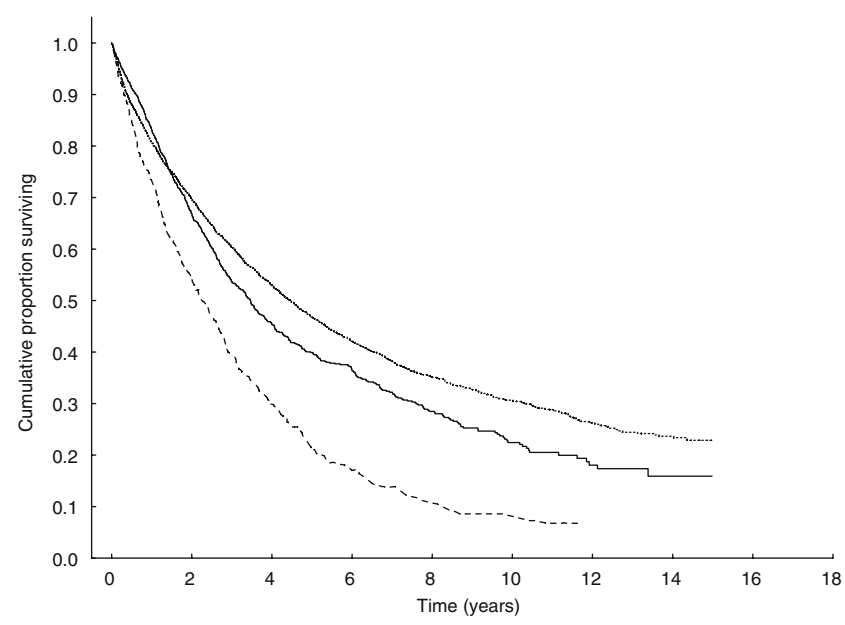

Fig. 1 Overall unadjusted survival rate in 1,105 type 1 diabetic (solid line), 718 type 2 diabetic (dashed line) and 6,598 non-diabetic (dotted line) patients with ESRD. $p<0.01$ for difference between the three groups 
Table 2 Multivariate Cox regression survival rate analysis in all 8,421 Danish patients with ESRD from 1990 to 2005

\begin{tabular}{llr}
\hline & HR $(95 \% \mathrm{CI})$ & $p$ value \\
\hline Time period (1995-1999 vs 1990-1994) & $0.82(0.76-0.88)$ & $<0.0001$ \\
Time period (2000-2004 vs 1995-1999) & $0.86(0.80-0.93)$ & $<0.0001$ \\
Type 1 vs non-diabetic patients & $1.66(1.53-1.81)$ & $<0.0001$ \\
Type 1 vs type 2 diabetic patients & $1.0(0.87-1.14)$ & 0.96 \\
All diabetic patients vs non-diabetic patients & $1.55(1.45-1.66)$ & $<0.0001$ \\
Transplanted patient vs all dialysis patients & $0.27(0.24-0.30)$ & $<0.0001$ \\
Age per decade & $1.39(1.36-1.42)$ & $<0.0001$ \\
Sex (male vs female) & $1.06(1.0-1.13)$ & 0.05 \\
\hline
\end{tabular}

4,733 events, $44 \%$ of patients censored, mean (SD) follow-up was 6.5 (4.1) years

$\mathrm{HR}<1$ denotes a better survival rate

$\mathrm{HR}>1$ denotes a poorer survival rate

more frequent in diabetic patients than in non-diabetic patients (Table 4).

Transplantation A total of 1,900 patients (15\% with type 1 diabetes, $2 \%$ with type 2 diabetes and $83 \%$ without diabetes) received a renal transplantation. Comparing the percentage within each of the three groups who received renal transplantation, we found comparable transplantation rates in type 1 diabetic patients $(26 \%)$ and non-diabetic patients (24\%), whereas few type 2 diabetic patients received transplantation (5\%). Due to the small numbers $(n=37)$ of transplanted type 2 diabetic patients, type 1 and type 2 diabetic patients were analysed together in the following. Excluding patients with type 2 diabetes from the analyses of transplanted patients did not change the results.

The mean age (SD) at the time of transplantation was comparable in diabetic and non-diabetic patients (42.6 [10] vs 42.0 [15] years). The mean time from start of ESRD to transplantation (waiting time) was $508 \pm 13$ days. The waiting time was significantly longer in time period 2 (594 \pm 23 days) than in time period $1(496 \pm 22$ days) and time period $3(397 \pm 18$ days) $(p<0.01)$. The mean waiting time in diabetic vs non-diabetic patients was similar $(530 \pm$ 30 days vs $503 \pm 14$ days, $p=0.42$ ). The number of transplantations performed in Denmark increased during the study period from 559 in time period 1, to 652 and 689 in the second and third time periods, respectively. The percentage of diabetic patients was not significantly different in the three time periods (16.6, 18.0 and 16.4\%, $p=0.45)$. The unadjusted survival rate in transplanted diabetic patients was poorer than in transplanted nondiabetic patient, whereas graft survival rate was similar in the two groups (Figs. 2 and 3). A multivariate Cox regression analysis including age at transplantation, sex, diabetes and time period demonstrated that diabetic patients had an $88 \%$ increased risk of dying $(\mathrm{HR}=1.88,95 \% \mathrm{CI}$ 1.50-2.36) compared with non-diabetic patients, whereas the graft survival rate in diabetic patients was comparable with non-diabetic patients $(\mathrm{HR}=1.14,95 \%$ CI $0.94-1.37$, $p=0.19$ ). The graft survival rate improved by $40 \%$ from the first to second time period $(\mathrm{HR}=0.60,95 \% \mathrm{CI} 0.51-0.72$, $p<0.0001)$ and by $37 \%(\mathrm{HR}=0.63,95 \%$ CI $0.45-0.88$, $p<0.01$ ) from time period 2 to 3 . Of the transplanted patients, $28 \%$ received a kidney from a living donor, a

Table 3 Improved survival rate per time periods in diabetic and non-diabetic patients with ESRD and treatments as specified in the time period 1990-2005

\begin{tabular}{|c|c|c|c|c|c|c|}
\hline Treatment & Time period & $\mathrm{HR}(95 \% \mathrm{CI})$ & $p$ value & Events $(n)$ & Censored $(\%)$ & Follow-up time (years) \\
\hline \multicolumn{7}{|l|}{ Dialysis } \\
\hline \multirow[t]{2}{*}{ Diabetic } & 2 vs $1, n=743$ & $0.81(0.69-0.95)$ & $<0.01$ & 693 & 7 & $7.3 / 12.2$ \\
\hline & 3 vs $2, n=1,233$ & $0.83(0.71 .0 .96)$ & $<0.02$ & 796 & 35 & $2.5 / 7.3$ \\
\hline \multirow[t]{2}{*}{ Non-diabetic } & 2 vs $1, n=2,633$ & $0.88(0.81 .0 .95)$ & $<0.01$ & 2,275 & 14 & $7.3 / 12.2$ \\
\hline & 3 vs $2, n=4,024$ & $0.88(0.80-0.96)$ & $<0.01$ & 2,300 & 43 & $2.5 / 7.3$ \\
\hline \multicolumn{7}{|l|}{ Transplantation } \\
\hline \multirow[t]{2}{*}{ Diabetic } & 2 vs $1, n=258$ & $0.47(0.30-0.77)$ & $<0.01$ & 99 & 62 & $7.4 / 12.2$ \\
\hline & 3 vs $2, n=197$ & $0.42(0.09-1.92)$ & $=0.26$ & 29 & 85 & $3.0 / 7.4$ \\
\hline \multirow[t]{2}{*}{ Non-diabetic } & 2 vs $1, n=1,181$ & $0.54(0.41-0.71)$ & $<0.001$ & 331 & 74 & $7.6 / 12.5$ \\
\hline & 3 vs $2, n=961$ & $0.98(0.56-1.75)$ & $=0.96$ & 91 & 91 & $3.0 / 7.6$ \\
\hline
\end{tabular}

Corrected for age and sex

Time period 1: 1990-1994; time period 2: 1995-1999; time period 3: 2000-2004

${ }^{a}$ Mean follow-up time in the two time periods that are compared 
Table 4 Causes of death in diabetic and non-diabetic patients with ESRD

\begin{tabular}{lll}
\hline & $\begin{array}{l}\text { Diabetic patients } \\
(n=1,161)\end{array}$ & $\begin{array}{l}\text { Non-diabetic patients } \\
(n=3,579)\end{array}$ \\
\hline Cardiac & 41 & $36^{* *}$ \\
Vascular & 14 & $12^{*}$ \\
Infection & 16 & 17 \\
Cancer & 2 & $10^{* * *}$ \\
Uraemia & 10 & 8 \\
Other & 17 & 17 \\
\hline
\end{tabular}

All values in $\%$

${ }^{*} p<0.05, * * p<0.01, * * * p<0.001$

percentage that was similar in diabetic and non-diabetic patients. The recipients of living donor kidneys were significantly younger than recipients of kidneys from deceased donors, with a mean age at the time of transplantation of 33.7 years vs 46.0 years $(p<0.0001)$, respectively. In a univariate analysis of the effect of living vs deceased kidney donor, we found significantly better survival rate among patients who received a kidney from a living donor $(\mathrm{HR}=0.51,95 \%$ CI $0.40-0.66, p<0.0001)$. However, when correcting for age, time period and diabetes, the difference was not significant $(\mathrm{HR}=0.80$, 95\% CI $0.62-1.05, p=0.11$ ).

Waiting-list status A total of 6,493 patients started RRT between 1 August 1994 and 1 January 2005 and were included in the analysis of the effect of waiting-list status. The demographic data in transplanted patients, waiting-list patients and non-transplantation candidate patients, classified using the 'intention to treat' method, are shown in Table 5. The unadjusted survival rate of diabetic and nondiabetic patients classified as transplanted, waiting-list

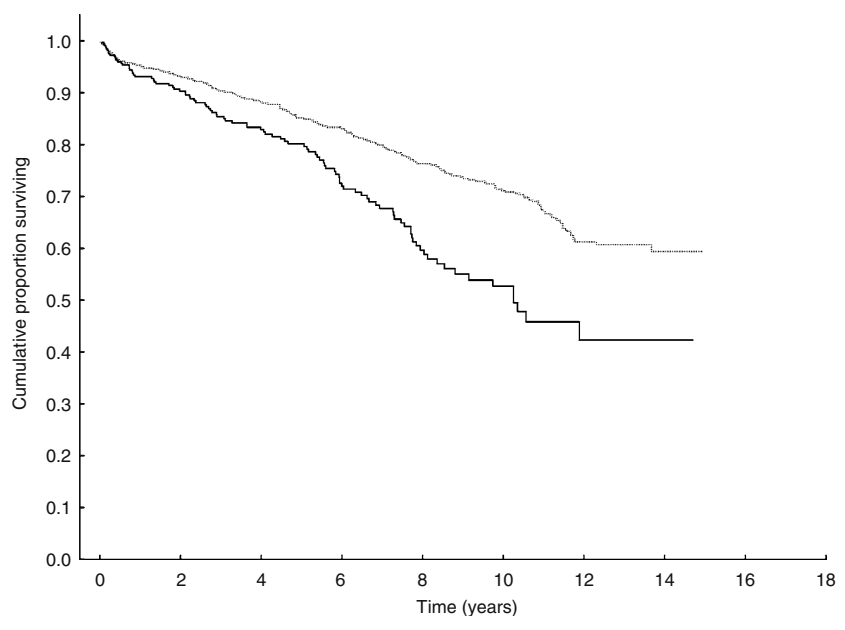

Fig. 2 Patient survival rate after first renal transplantation in 323 diabetic (solid line) vs 1,577 non-diabetic (dotted line) patients. $p<0.0001$

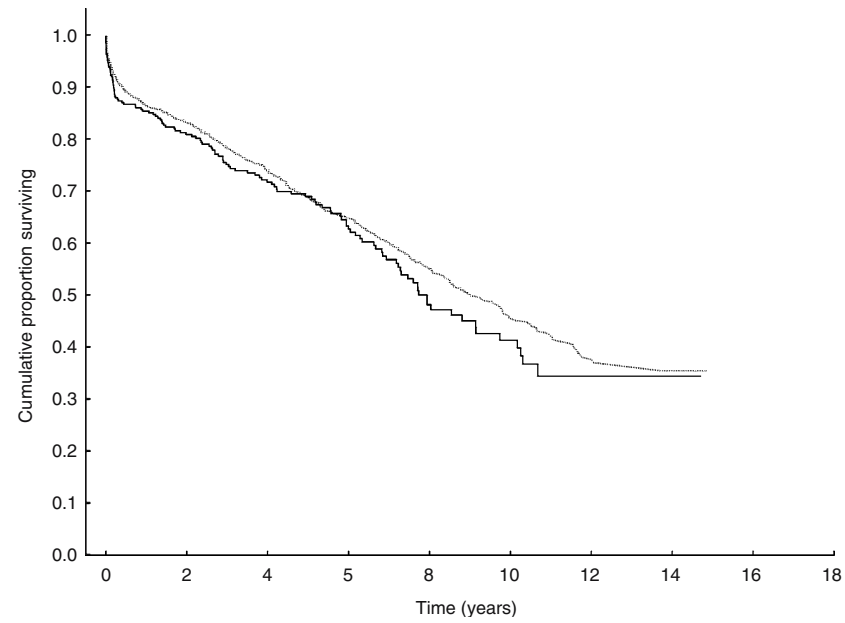

Fig. 3 Graft survival rate in 323 diabetic (solid line) vs 1,577 nondiabetic (dotted line) patients. $p=0.64$

without being transplanted and non-transplantation candidates respectively is shown in Figs. 4 and 5. The results of the multivariate Cox regression analyses in diabetic and non-diabetic patients are shown in Table 6. In transplanted diabetic patients the risk of dying was reduced by $79 \%$ compared with waiting-list patients who did not receive a renal transplantation. For the transplanted non-diabetic patients the risk of dying decreased by $60 \%$ compared with waiting-list patients. It thus seems that renal transplantation improves survival rate even more among diabetic patients suitable for transplantation than among non-diabetic counterparts. We found similar results in both diabetic and nondiabetic patients when patients who received living donor transplantation were excluded and waiting-list patients were compared only with patients who received a kidney from a deceased donor (data not shown).

\section{Discussion}

This epidemiological study of all patients with ESRD in Denmark between 1990 and 2005 demonstrated an improved survival rate over time, especially in patients who received a renal transplantation and also in patients with diabetes. Our study extends the observation of Meier-Kriesche et al. [14], who reported a similar trend in a study comparing dialysis patients on the waiting-list and transplant recipients in the USA up to 1996. During a 7-year time period the mortality risk in dialysis patients on the waiting-list and transplanted patients decreased by 23 and $30 \%$, respectively. In our study the mortality risk in diabetic dialysis patients was reduced by 19 and $17 \%$ per five calendar years, respectively; in diabetic transplanted patients it was reduced by $53 \%$ from time period 1 to time period 2 and by $58 \%$ from time period 2 to time period 3 . When evaluating the reduction in mortality 
Table 5 Demographic data in 6,493 patients with ESRD

\begin{tabular}{llll}
\hline & $\begin{array}{l}\text { Transplanted patients } \\
(n=1,239)\end{array}$ & $\begin{array}{l}\text { Waiting-list patients } \\
(n=517)\end{array}$ & $\begin{array}{l}\text { Non-transplantation candidates } \\
(n=4,737)\end{array}$ \\
\hline Mean (SD) age (years) at start of ESRD & $40.8(14)$ & $48.5(12)$ & $66.2(12)$ \\
Percentage with type 1 diabetes & 15 & 17 & 11 \\
Percentage with type 2 diabetes & 2 & 5 & 13 \\
\hline
\end{tabular}

risk of transplanted diabetic patients in the third time period, it should be noted that the number of events and the observation period are relatively small; a change in selection criteria might also have occurred. The cardiac evaluation of diabetic patients before entering the waiting-list has been intensified since 2000 in order to diagnose and treat coronary stenoses prior to transplantation. However, the number of performed transplantations increased during the whole study period and the fraction of diabetic patients who received transplantation has remained unchanged.

Similarly, the graft survival rate in the USA improved by $4.2 \%$ per year between 1988 and 1996, $(p<0.001)$ [15], whereas the graft survival rate in Denmark improved by 40 and $37 \%$ per five calendar years, respectively.

In our study, the overall adjusted mortality risk was similar in type 1 and type 2 diabetic patients. The mortality risk in the combined group of diabetic patients was 55\% higher than in non-diabetic patients. This is in accordance with a Canadian study of more than 20,000 patients treated with dialysis, where patients with diabetes had a $73 \%$ increased mortality risk compared with patients with glomerulonephritis as the primary renal disease [16]. The improved survival rate over time in our study may be due to the more intensive treatment seen in diabetic and nondiabetic patients both before and after reaching ESRD. Especially aggressive antihypertensive treatment, improved

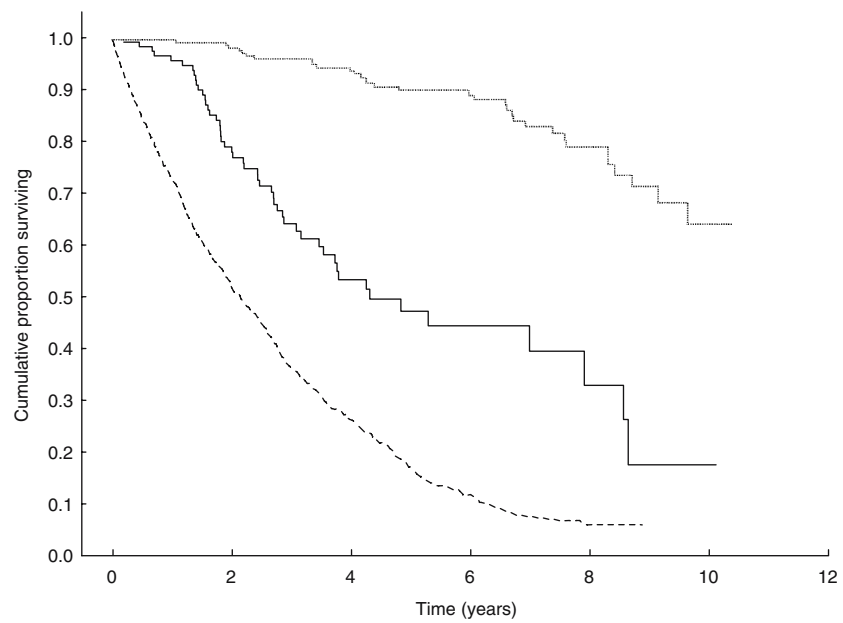

Fig. 4 Survival rate in 1,448 type 1 and 2 diabetic patients according to transplantation (dotted line) and waiting-list (solid line) status. Dashed line, non-transplantation candidates. $p<0.0001$ glycaemic control and smoking cessation have been shown to improve the survival rate in diabetic patients with nephropathy [17]. Moreover the treatment of uraemia has improved during the last 20 years (e.g. treatment of anaemia and vitamin D deficiency, control of blood pressure, improved dialysis methods and optimised immunosuppressive treatment in transplanted patients). The poorer outcome in diabetic patients compared with nondiabetic patients may be due to the higher prevalence of cardiovascular diseases both before and after start of RRT.

Transplantation In this study a similar fraction of incident type 1 diabetic and incident non-diabetic patients received a renal transplantation. However, the patient survival rate after transplantation was significantly poorer in diabetic than in non-diabetic patients, whereas the graft survival rate was similar in the two groups. These findings are in line with a Swedish report [18], where the 5-year survival rates in diabetic vs non-diabetic patients were 79.8 vs $86.8 \%$ in transplanted patients and 14.5 vs $25.5 \%$ in patients treated with dialysis. In the present study the corresponding 5-year survival rates were: 80 vs $85 \%$ for transplanted patients and 18 vs $30 \%$ for dialysis patients. Two other studies also report poorer patient survival rates but similar graft survival rates in transplanted diabetic patients [19, 20], whereas other studies have found a similar survival rate in diabetic and non-diabetic patients for up to

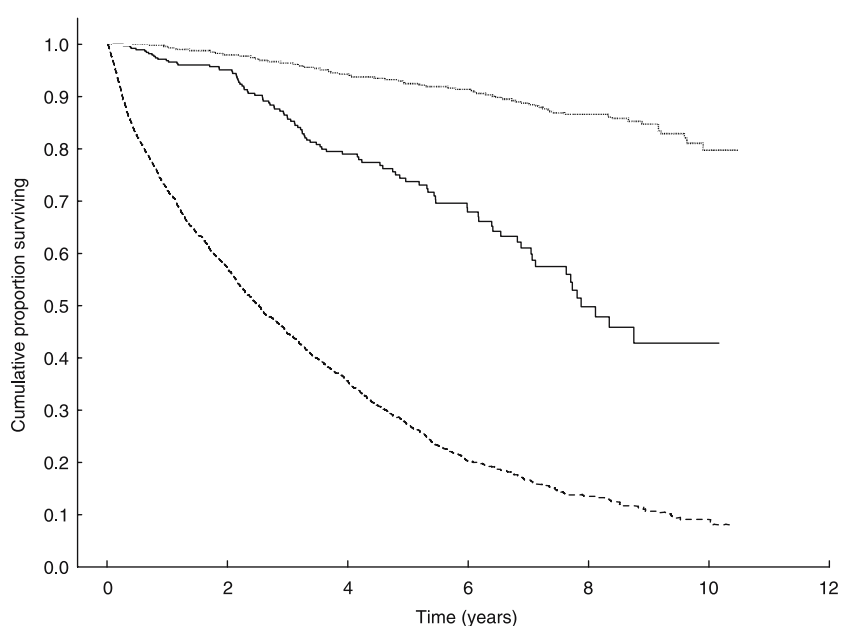

Fig. 5 Survival rate in 5045 non-diabetic patients according to transplantation (dotted line) and waiting-list (solid line) status. Dashed line, non-transplantation candidates. $p<0.0001$ 
Table 6 Comparison of survival rates in transplanted, waiting-list and non-transplantation candidate patients with and without diabetes

\begin{tabular}{|c|c|c|c|}
\hline Patient category & $\operatorname{HR}(95 \% \mathrm{CI})$ & $n$ & $p$ value \\
\hline \multicolumn{4}{|l|}{ Diabetic } \\
\hline Transplanted vs waiting-list & $0.21(0.13-0.34)$ & 329 & $<0.0001$ \\
\hline Waiting-list vs non-candidates & $0.75(0.55-1.02)$ & 1,236 & $<0.07$ \\
\hline \multicolumn{4}{|l|}{ Non-diabetic } \\
\hline Transplanted vs waiting-list & $0.40(0.30-0.55)$ & 1,427 & $<0.0001$ \\
\hline Waiting-list vs non-candidates & $0.53(0.42-0.65)$ & 4,016 & $<0.0001$ \\
\hline
\end{tabular}

Classified according to the intention to treat method, and corrected for age, sex and time period in a multivariate Cox regression model. $\mathrm{HR}<1$ denotes better a survival rate in the first group than in the second group

5 years after transplantation [21-23]. Nevertheless, receiving a renal transplantation was the strongest predictor of survival rate in both diabetic and non-diabetic patients, with a $73 \%$ lower mortality risk in transplanted patients compared with patients treated with dialysis, even when correcting for age, sex, calendar time and presence of diabetes.

In order to avoid some of the selection bias, we compared transplanted patients with dialysis patients on the waiting-list who did not receive a renal transplantation. We still found a significantly better survival rate in transplanted patients, especially in the group of patients with diabetes. The fact that the waiting-list patients were significantly older than the transplanted patients (48.5 vs 40.8 years, $p<0.0001$ ) indicates that selection bias was not completely abolished. However, when correcting for age, sex and time period, transplantation was still associated with a markedly decreased mortality risk compared with patients on the waiting list. In order to further minimise the selection bias between transplanted and waiting-list patients, we excluded patients who received living donor transplantation and compared waiting-list patients only with patients who received a kidney from a deceased donor (data not shown), but still found a comparably better survival rate in the transplanted patients. However, selection bias between transplanted and waiting-list patients may still exist in our study, and it is impossible to estimate how much this affects our results.

The fact that the survival rate was only slightly better in waiting-list patients than in non-transplantation candidates, yet much better in transplanted patients also suggests that the impact of transplantation is independent of the selection criteria for transplantation. In the analysis of the effect of transplantation compared with all dialysis patients and patients on the waiting-list, we used the 'intention-to-treat' method and thereby did not consider when patients were temporarily or permanently withdrawn form the waiting list. However, using the 'as treated' method for statistical analysis did not produce any significant differences in the mortality risk for any of the patient groups (data not shown).

The gain in life expectancy among transplanted patients (living and deceased donor) was proportionally higher in diabetic patients than in non-diabetic patients. These results are consistent with other studies of the survival rate in transplanted patients compared with waiting-list patients on dialysis [12, $14,24]$. Wolfe et al. also found a proportionally higher benefit of transplantation, with annual death rates of 19.9 , 10.8 and 5.6 deaths per 100 patient-years in diabetic patients compared with 13.3, 4.3 and 3.0 deaths per 100 patient-years in non-diabetic patients, all dialysis patients, waiting-list patients and transplanted patients, respectively [12].

In this national register-based study we did not have any information on co-morbidity or clinical parameters such as blood pressure, $\mathrm{HbA}_{1 \mathrm{c}}$, haemoglobin, cholesterol, BMI or smoking status. Therefore we were not able to relate health status in the different patient subgroups at the start of ESRD to the mortality risks. Neither were we able to investigate the associations of clinical parameters with the survival rate. However, the study is based on the entire Danish ESRD population, registration is $100 \%$ and goes up to the year 2005. Moreover, all patients have been treated by the same public healthcare system and the patients are relatively homogeneous regarding race, the majority being white Europids.

We conclude that the survival rate in patients with ESRD has improved during the last 15 years, especially in patients with diabetes. Thus it seems that the improved and more intensive treatment of diabetic patients, starting at first occurrence of microalbuminuria, has not only the potential to prevent or postpone ESRD, but might also improve the survival rate after start of ESRD. The normalisation in kidney function seen in transplanted patients seems to improve the survival rate, even after adjustment for possible selection bias. Among patients with diabetes the survival rate benefit of renal transplantation was significantly larger than in non-diabetic patients. In contrast to earlier trends of reluctance in offering renal transplantation to diabetic patients, we conclude that transplantation should be offered to diabetic patients with ESRD whenever possible.

Acknowledgements We thank The Danish Diabetes Association and the Danish Kidney Association, who supported the work.

Duality of interest There is no duality of interest to declare. 


\section{References}

1. The Diabetes Control and Complications Trial Research Group (1993) The effect of intensive treatment of diabetes on the development and progression of long-term complications in insulin-dependent diabetes mellitus. N Engl J Med 329:977-986

2. UK Prospective Diabetes Study (UKPDS) Group (1998) Intensive blood-glucose control with sulphonylureas or insulin compared with conventional treatment and risk of complications in patients with type 2 diabetes (UKPDS 33). Lancet 352:837-853

3. Adler AI, Stratton IM, Neil HA et al (2000) Association of systolic blood pressure with macrovascular and microvascular complications of type 2 diabetes (UKPDS 36): prospective observational study. Br Med J 321:412-419

4. Brenner BM, Cooper ME, de Zeeuw D et al (2001) Effects of losartan on renal and cardiovascular outcomes in patients with type 2 diabetes and nephropathy. N Engl J Med 345:861-869

5. Collins R, Armitage J, Parish S, Sleigh P, Peto R (2003) MRC/ BHF Heart Protection Study of cholesterol-lowering with simvastatin in 5963 people with diabetes: a randomised placebocontrolled trial. Lancet 361:2005-2016

6. Gaede P, Vedel P, Parving HH, Pedersen O (1999) Intensified multifactorial intervention in patients with type 2 diabetes mellitus and microalbuminuria: the Steno type 2 randomised study. Lancet 353:617-622

7. Parving HH, Lehnert H, Brochner-Mortensen J, Gomis R, Andersen S, Arner P (2001) The effect of irbesartan on the development of diabetic nephropathy in patients with type 2 diabetes. N Engl J Med 345:870-878

8. The Diabetes Control and Complications (DCCT) Research Group (1995) Effect of intensive therapy on the development and progression of diabetic nephropathy in the Diabetes control and complications trial. Kidney Int 47:1703-1720

9. Sorensen VR, Hansen PM, Heaf J, Feldt-Rasmussen B (2006) Stabilized incidence of diabetic patients referred for renal replacement therapy in Denmark. Kidney Int 70:187-191

10. Gaylin DS, Held PJ, Port FK et al (1993) The impact of comorbid and sociodemographic factors on access to renal transplantation. JAMA 269:603-608

11. Satayathum S, Pisoni RL, McCullough KP et al (2005) Kidney transplantation and wait-listing rates from the international Dialysis Outcomes and Practice Patterns Study (DOPPS). Kidney Int 68:330-337

12. Wolfe RA, Ashby VB, Milford EL et al (1999) Comparison of mortality in all patients on dialysis, patients on dialysis awaiting transplantation, and recipients of a first cadaveric transplant. $\mathrm{N}$ Engl J Med 341:1725-1730

13. Locatelli F, Pozzoni P, Del Vecchio L (2004) Renal replacement therapy in patients with diabetes and end-stage renal disease. J Am Soc Nephrol 15(Suppl 1):S25-S29

14. Meier-Kriesche HU, Ojo AO, Port FK, Arndorfer JA, Cibrik DM, Kaplan B (2001) Survival improvement among patients with endstage renal disease: trends over time for transplant recipients and wait-listed patients. J Am Soc Nephrol 12:1293-1296

15. Hariharan S, Johnson CP, Bresnahan BA, Taranto SE, McIntosh MJ, Stablein D (2000) Improved graft survival after renal transplantation in the United States, 1988 to 1996. N Engl J Med 342:605-612

16. Rao PS, Schaubel DE, Saran R (2005) Impact of graft failure on patient survival on dialysis: a comparison of transplant-naive and post-graft failure mortality rates. Nephrol Dial Transplant 20:387391

17. Astrup AS, Tarnow L, Rossing P, Pietraszek L, Riis HP, Parving HH (2005) Improved prognosis in type 1 diabetic patients with nephropathy: a prospective follow-up study. Kidney Int 68:12501257

18. Schon S, Ekberg H, Wikstrom B, Oden A, Ahlmen J (2004) Renal replacement therapy in Sweden. Scand J Urol Nephrol 38:332339

19. Lufft V, Dannenberg B, Schlitt HJ, Pichlmayr R, Brunkhorst R (2004) Cardiovascular morbidity and mortality in patients with diabetes mellitus type I after kidney transplantation: a case-control study. Clin Nephrol 61:238-245

20. Revanur VK, Jardine AG, Kingsmore DB, Jaques BC, Hamilton DH, Jindal RM (2001) Influence of diabetes mellitus on patient and graft survival in recipients of kidney transplantation. Clin Transplant 15:89-94

21. Bittar J, Cepeda P, de la Fuente J, Douthat W, de Arteaga J, Massari PU (2006) Renal transplantation in diabetic patients. Transplant Proc 38:895-898

22. Ekberg H, Christensson A (1996) Similar treatment success rate after renal transplantation in diabetic and nondiabetic patients due to improved short- and long-term diabetic patient survival. Transpl Int 9:557-564

23. Romming SV, Schwartz SS, Feldt-Rasmussen B (2006) Longterm graft and patient survival following renal transplantation in diabetic patients. Scand J Urol Nephrol 40:247-251

24. Brunkhorst R, Lufft V, Dannenberg B, Kliem V, Tusch G, Pichlmayr R (2003) Improved survival in patients with type 1 diabetes mellitus after renal transplantation compared with hemodialysis: a case-control study. Transplantation 76:115-119 